\title{
LÍMITES PARA LOS DELITOS DE PREPARACIÓN: CRITERIOS RESTRICTIVOS PARA SU INCLUSIÓN EN EL CÓDIGO PENAL
}

\author{
Limits for preparation crimes: restrictive criteria for \\ inclusion in the criminal code
}

\author{
Roberto Cruz Palmera ${ }^{1}$ \\ Profesor Doctor (LL.M.) \\ Universidad Autónoma del Caribe
}

http://dx.doi.org/10.18543/ed-68(1)-2020pp257-285

Recibido: 30.04 .2020

Aceptado: 12.06 .2020

\section{Resumen}

La tesis que aquí se defiende se sustenta en algunos aportes doctrinales, pero especialmente en las contribuciones de los tribunales españoles. En esta contribución se vuelve a tratar, una vez más, el problema de los delitos de preparación; no se trata de una nueva crítica de la incompatibilidad de los delitos de preparación con los principios básicos del Derecho Penal. Por el contrario, se exponen criterios limitadores para admitir su inclusión. Se asume, que dentro de la excepcionalidad que supone la incriminación de la fase de preparación, es posible incriminar dicha fase, únicamente, para casos puntuales.

\section{Palabras clave}

Poder punitivo del Estado. Excepción. Preparación.

${ }^{1}$ Prof. Dr. Roberto Cruz Palmera (LL.M.), Universidad Autónoma del Caribe, Barranquilla, Colombia.

Para las citas jurisprudenciales opté por la base de datos vLex España. 


\section{Abstract}

The thesis defended here is based on some doctrinal contributions, but especially on the contributions of the courts. In this contribution the problem of preparatory crimes is dealt with again; this is not a new criticism of the incompatibility of preparatory crimes with the basic principles of criminal law. On the contrary, limiting criteria are exposed to admit its inclusion. It is assumed that, within the exceptional nature of the incrimination of the preparation phase, it is possible to incriminate said phase, only for specific cases.

\section{Keywords}

Punitive power of the State. Exception. Preparation. 


\begin{abstract}
SuMARIO: I. El PROBlema. II. Distinción ENTRE ACTOS PREPARATORIOS PUNIBLES Y «DELITOS DE PREPARACIÓN». III. REVISIÓN DE ALGUNOS AUTORES. IV. UNIÓN DE SUJETOS EN LOS «ACTOS PREPARATORIOS PUNIBLES»Y Y SUS CONSECUENCIAS DOGMÁTICAS. V. LA POSTURA JURISPRUDENCIAL. VI. SOBRE LA ATENUACIÓN OBLIGATORIA DE LA PENA EN LOS «DELITOS DE PREPARACIÓN». VII. REFLEXIÓN PERSONAL. VIII. CONCLUSIONES. Bibliografía.
\end{abstract}

\title{
I. EL PROBLEMA
}

1. Una de las figuras de anticipación más controvertidas en nuestra legislación penal son los denominados «delito de preparación». Desde nuestro punto de vista, el adelantamiento de las barreras de protección que caracteriza a estas normas penales obliga a trabajar en la solución, de por los menos, tres puntos problemáticos. El primero, ofrecer criterios específicos para interpretar y aplicar estos delito de manera restrictiva; el segundo, una elaboración de motivos para la disminución de las penas actualmente previstas en esas normas; el tercero, criterios para limitar la inclusión de delitos de preparación en el Código Penal. Debido a la complejidad de la materia, en este trabajo, revisaremos, si bien de manera sucinta, algunos aspectos relacionados con los dos primeros aspecto; de esa manera será posible la elaboración de criterios restrictivos para incluir «delito de preparación» en la legislación penal.

Los «delitos de preparación» sancionan una fase previa a la tentativa de un delito ${ }^{2}$, pues el legislador incrimina formas o modos concretos de preparación con los cuales se realizará un determinado delito fin o tipo base. Son, a su vez, distintos a otros métodos de anticipación como los delitos de peligro y delitos de emprendimiento, aunque se les puede identificar con alguna de estas últimas categorías debido a la anticipación que también representan ${ }^{3}$. Por obvio que parezca, debido a la excesiva extensión de las barreras de punición, no son pocos los problemas que presentan los «delitos de preparación», pongo por caso, su evidente contradicción con el principio de proporcionalidad penal, pues las sanciones previstas por el legislador no responden precisamente a la lógica que demanda dicho principio, en algunos casos se sanciona, de la misma manera, tanto el resultado como la preparación de un ilícito ${ }^{4}$. También, queda en duda la compatibilidad con otros principios

2 Véase, STS 747/2017, 21 de Noviembre de 2017.

3 Véase, STS 241/2019, 9 de Mayo de 2019.

4 Véase, por ejemplo, las consecuencias jurídicas previstas para los siguientes delitos: art. 248.2, preparación de una defraudación informática; b), art. 399 bis 2, preparación de 
básicos como el principio de culpabilidad, es posible sancionar al alguien por acciones ejecutadas por otro, pienses, en el castigo de la posesión o tenencia de instrumentos prohibidos que han sido elaborados o fabricados por un sujeto distinto al poseedor ${ }^{5}$. Además, podemos añadir la cuestionable sanción de la tentativa en estas normas penales, pues al estar ubicadas en la parte especial es de total aplicación el art. 16.1 del Código Penal ${ }^{6}$; en similar dirección, un asunto de necesaria revisión, es, a mi juicio, el desistimiento voluntario, ya que al estar ligado a la tentativa, será necesario determinar si en realidad es posible determinar cuándo un sujeto desiste de la preparación delictiva y cuándo la conducta realizada despliega un riesgo típicamente relevante de tentativa ${ }^{7}$. Ahora bien, en esta contribución no pretendo agotar todos los problemas que caracterizan a los delitos de preparación, por el contrario, me centraré, en lo esencial, en brindar argumentos para decir cuándo en un sistema penal respetuoso de los postulados que sostienen un Estado de Derecho pueden ser incluidas esta clase de figuras de anticipación ${ }^{8}$. Para ello, empiezo «desligando» a los «delitos de preparación» de una figura ampliamente estudiada en nuestro Derecho penal: «actos preparatorios punible»; por ser considerada la excepción respecto a la sanción de conductas de estricta preparación ${ }^{9}$. Después repasaré algunas valoraciones doctrinales respecto a la inclusión de «delitos de preparación», para finalmente llegar a mi conclusión. En esta última parte, la tesis, propongo dos criterios para incluir «delitos de preparación» en el Código Penal. Y finalmente, expondré mi conclusión.

\section{DISTINCIÓN ENTRE ACTOS PREPARATORIOS PUNIBLES Y «DELITOS DE PREPARACIÓN»}

En el código penal español contamos con una figura de anticipación que sanciona actos de estricta preparación, los supuestos que se sancionan mediante esta figura son la excepción al castigo de conductas en estado de

fraude mediante tarjeta de crédito, débito o cheque de viaje falsificado; art. 400, preparación de falsificación de documento público o privado. En este grupo la pena prevista es exactamente igual a la realización del tipo doloso del respectivo delito fin que se prepara.

5 Véase, ampliamente, STS 956/2013, 17 de Diciembre de 2013.

6 Véase, STS 673/2015, 4 de Noviembre de 2015.

7 Yesid Reyes Alvarado, El delito de tentativa, (Montevideo/Buenos Aires: BdF, 2016), 106-111.

${ }^{8}$ Francisco Muñoz Conde y Mercedes García Arán, Derecho Penal. Parte especial,

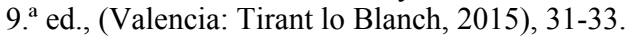

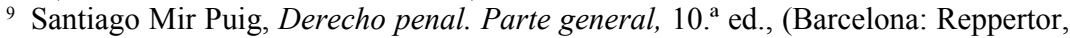
2015), 350-351. 
preparación ${ }^{10}$. De un lado, la conspiración para delinquir que junto con la proposición se recoge en el art. 17. De otro lado, la provocación que incluye consigo la apología, art. 18, conservando un marco penal inferior en uno o dos grados al señalado para los correspondientes delitos que se prepara ${ }^{11}$.

La distinción entre «actos preparatorios punibles» y «delitos de preparación» tiene gran relevancia en nuestro análisis, pues si pretendemos ofrecer criterios limitadores para la inclusión de los «delitos de preparación», es necesario partir de un análisis comparativo entre ambas figuras de anticipación ${ }^{12}$, un asunto que no podría elaborarse prescindiendo del estudio de los «actos preparatorios punibles», pues, como se adelantó, se trata de la «excepción» al castigo de conductas en estado de preparación ${ }^{13}$. El problema presenta notoria repercusión en la interpretación de esta clase de delitos. Por ejemplo: con el precepto que sanciona los supuestos para preparar la incitación o reforzamiento moral para ejecutar desórdenes públicos (art. 559) ${ }^{14}$ A casi nadie se le oculta que la mera preparación de un acto que pretenda alterar el orden público es desde todo punto de vista inofensivo si hablamos de una estricta preparación ${ }^{15}$. Al parecer, el citado precepto se configura como una tentativa de inducción extensiva y se podría concebir además como un tipo de incitación, pero no se trata de una inducción directa, sino generalizada $^{16}$.

10 Véase, STS 480/2009, 22 de Mayo de 2009.

11 Francisco Muñoz Conde y Mercedes García Arán, Derecho Penal..., 479; STS 214/2018, 8 de Mayo de 2018.

12 Véase, STS 277/2015, 3 de Junio de 2015.

${ }^{13}$ En el Código Penal abundan ejemplos: arts. 270.6, 286.1, 345, 371.1, 386.2; véase además, STS 234/2017, 4 de Abril de 2017.

${ }^{14}$ En el Código Penal abundan ejemplos: arts. 270.6, 286.1, 345, 371.1, 386.2.

15 A la luz del precepto contenido en el art. 559, resulta punible la redacción de un discurso que cuente con unos argumentos tan convincentes que pueda generar un desorden público. Esta conducta puede imputarse tanto al redactor del escrito como por otra persona. Cfr. Ignacio. F. Benítez Ortúzar, «Delitos contra el orden público», en Lorenzo Morillas Cueva dir., Sistema de Derecho penal. Parte Especial, 2. ${ }^{\text {ed., }}$ (Madrid: Dikinson, 2016), 1361-1363.

${ }^{16}$ El hecho de que la incitación en este precepto no tenga que ser directa genera varios interrogantes. A nuestro juicio contradice la lógica interna del legislador. La cuestión toma sentido cuando nos preguntamos: por qué, en la mayoría de los casos, castigamos con la pena prevista para los autores en supuestos de inducción. El fundamento de ese marco penal es conocido por todos, pero posiblemente ha sido olvidado por el legislador. Así pues, si aceptamos que la peligrosidad de la inducción se fundamenta en el incremento sustancial del riego mediato para un bien jurídico. El inductor es quien logra despertar y generar la idea criminal, por consiguiente se interpreta como «elemento» determinante de una concreta voluntad dolosa que logra ser trasladada en otro o, lo que es lo mismo, despierta en alguien la firme decisión de cometer un delito. De manera que su entidad 
Los «actos preparatorios punibles» pueden entenderse, por un importante sector de la doctrina, como formas de "participación intentada» ${ }^{17} \mathrm{o}$; por otro sector, como «formas previas a la codelincuencia del hecho consumado» ${ }^{18}$. A nuestro parecer, entendemos que son fases anteriores a la participación, puesto que están encaminadas a lesionar un interés jurídico, pero se enmarcan en un plan delictivo (o proyecto criminal) ${ }^{19}$. De manera que nos encontramos ante actos de preparación para cometer un delito, por eso, para admitir su castigo no es necesario la creación de un riesgo relevante en la fase de planificación, y esto requiere una ideación delictiva acompañada de algunos presupuestos específicos. Por eso decimos que la infracción penal que se prepara ha de ser, generalmente, lo suficientemente relevante para ser de interés por el Derecho Penal. Ahora bien, en los «actos preparatorios punibles» es notorio el incremento de la percepción de peligrosidad que se evidencia con la unión de sujetos que buscan y quieren causar una lesión, y por eso se decide dar un adelanto e intervenir antes de que se produzca el resultado de lesión a un bien jurídico. Dicha unión de fuerzas, a mi juicio, coloca en un estado de indefensión a la potencial víctima.

Sabemos que tanto los «actos preparatorios punibles» como los «delitos de preparación» son instrumentos que se ubican en el terreno de la preparación delictiva; y que la delimitación entre ambas figuras puede realizarse estudiando el alcance de la expresión «formas intentadas de participación», elemento que se ausenta en los «delitos de preparación» frente a los «actos preparatorios punibles»; así como de otras formas de anticipación ${ }^{20}$. La diferencia entre una y otras formas de anticipación delictiva parecer estar, por tanto, en la intensidad o grado de la peligrosidad representada para el legislador.

cualitativa requiere -entre otros presupuestos- que sea no sólo «directa», sino que se acompañe de una carga lo suficientemente relevante a efectos de imputación. Sin duda alguna, la relación personal e inmediata entre los sujetos incrementa de manera significativa el riesgo para el bien jurídico, asimismo, el hecho de despertar una decisión para delinquir que no existía ex ante en la mente del inducido, por lo tanto, la valoramos como causa jurídicamente relevante del resultado. Considero que estos requisitos hacen admisibles la equiparación del marco penológico a pesar de que quien actúe sea otro. Sin embargo, en varios «delitos de preparación», algunas de estas valoraciones no están presentes.

17 Francisco Muñoz Conde y Mercedes García Arán, Derecho penal ..., 479-480. Para estos autores, dada la naturaleza de los «actos preparatorios punibles» no pueden separarse -por decirlo de algún modo- del principio de accesoriedad limitada. También aseguran que el criterio de dicho principio solo se podría paletear de manera hipotética, puesto que en los «actos preparatorios punibles» no es necesario realizar el plan delictivo.

18 Santiago Mir Puig, Derecho penal..., 351.

19 Véase, STC 177/2015, 22 de Julio de 2015.

${ }^{20}$ Santiago Mir Puig, Derecho penal..., 346-347. 
Expuestas algunas diferencias entre las dos figuras de adelantamiento objeto de ocupación, pasemos ahora a explicar qué es lo que caracteriza en realidad a un instrumento tan controvertido como los «delitos de preparación». Sobre el particular, cabe hacer, por de pronto, tres matizaciones. La primera, casi nadie duda que no requieren la vinculación de sujetos para la realización del plan delictivo. La segunda, se trata de un instrumento que puede ser empleado para proteger cualquier clase de bien jurídico ya sea individual o colectivo, es decir, no se limita su aplicación para determinados intereses sociales, por lo tanto, no es un recurso de urgencia (si me permite la expresión). Asimismo, tampoco se reduce su aplicación para un grupo de agresiones o ataques específicos; ya que existe una variedad de conductas incriminadas. La tercera, no se trata de una técnica de protección para bienes jurídicos irrecuperables (aunque se emplea en algunos supuestos) ${ }^{21}$.

A pesar de estas observaciones, la sanción que el legislador establece para los «delitos de preparación» supera al marco penológico esperado ${ }^{22}$. Nos interesa conocer cuál es la razón que fundamenta la imposición de un marco penal tan controvertido como el actualmente previsto en la legislación espa$\tilde{n}_{0} a^{23}$. Mejor dicho, nos preguntamos qué es lo que invita al legislador a castigar, cada vez más, actos de preparación con igual pena a la prevista en la realización del respectivo delito base si desde todo punto de vista la

${ }^{21}$ El hecho de anticipar la intervención para bienes jurídicos tan dispares como el patrimonio económico, art. 386; la integridad sexual, art. 183 ter 1; orden público, art. 557.2; administración pública, art. 428; propiedad intelectual, art. 270.6, nos inclina a la afirmación de que los «delitos de preparación» se distancian de ser figura de corte excepcional, pues tanto bienes jurídicos recuperables (art. 248.2 b]) como irrecuperables (art. 183 ter 1) se pueden proteger de forma anticipada con esta técnica.

${ }^{22}$ El legislador renuncia-inclusive- a elementos objetivos que describen los propios tipos, equipara la preparación de un acto de terrorismo con el adiestramiento para cometer un acto terrorista (art. $575 \mathrm{CP}$ ). Aquí surgen - cuanto menos- una objeción; aunque el legislador no «sepa» con certeza cuando el sujeto que se prepara realizará el injusto, lo cierto es que da por sentado que lo hará. Pues no espera hasta el inicio, sino que se adelanta, castigando su posible intención. Un adelantamiento como este impide al sujeto la decisión (libre) de renunciar a la acción criminal. Por descontado, nos referimos al desistimiento voluntario que habrá de ser valorado en estos preceptos, pues no hay que desestimar la posibilidad de reflexión que deriva en un arrepentimiento profundo para supuestos como la preparación y ejecución de un acto terrorista, así como de otros delitos.

${ }^{23}$ Veamos la siguiente cuestión. Si el legislador prevé una pena inferior en uno o dos grados es porque atiende tanto a la peligrosidad que genera el intento como al grado de ejecución, en el mayor número de casos mediante daño causado. Si esto es lo que, en parte, hace posible emitir una sanción como la de la tentativa, creo que deberíamos insistir en atender a un marco penológico, cuento menos, distintamente inferior al previsto hasta ahora en los «delitos de preparación». 
preparación no representa ni lesión ni peligro ni una misma impresión que la producida en la realización perfecta del tipo base ${ }^{24}$.

La doctrina, históricamente, se centró en determinar los niveles de necesidad para castigar actos preparatorios, lo que es, incriminación de conductas preparatoria para delitos que se recogen en la Parte Especial del Código Penal. Resumidamente: Se discutió si había que entender a la necesidad concreta para anticipar la intervención de algunos bienes jurídicos; o a la necesidad abstracta de salvar cualquier clase de bien jurídico (sistema abierto de incriminación). Pero finalmente se entendió que una fórmula abierta no era la más adecuada, porque nos podría conducir a limitar demasiado la libertad ${ }^{25}$.

Por eso, atendemos ahora a la necesidad concreta, esto es, todo "acto preparatorio» para ser sancionado o considerado «punible» deberá estar específicamente conectado a un tipo previsto en la Parte Espacial y cumplir con los presupuestos exigidos para cada modalidad ${ }^{26}$. («conspiración»,, «provocación», «proposición»...).

Si bien se seleccionaron una serie de bienes jurídicos a razón de su importancia en un primer momento, lo cierto es que luego el legislador ha incluido de manera progresiva más «actos preparatorios punibles»» ${ }^{27}$ en el Código

${ }^{24}$ A todo esto, para que un acto de estricta preparación sea considerado como delito y rompa el criterio lógico interno en términos penológicos deberán -desde nuestro juicioestar presentes una serie de presupuestos que soporten esta ruptura, de lo contrario, se tendría que abogar por una desincriminación para los preceptos. O, de otro modo, defender una interpretación ajustada a los principios limitadores del poder punitivo. Por tanto, se requiere la presencia de elementos adicionales que fundamenten y justifiquen su equiparación con el tipo consumado. En esta dirección, para aceptar las penas actualmente previstas para dichas conductas tipificadas en el estadio de la preparación, tendrán que representar una eficacia lesiva desde dicho estado, lo que es, generar una impresión de un alto riesgo desde la preparación. También, sería adecuado atender a este recurso a razón de la gravedad del bien jurídico. Por ejemplo, la capacidad de defensa por parte del titular (vida e integridad sexual, menores o incapaces).

${ }^{25}$ Así como se decidió «cerrar la válvula de escape» para la sanción de todas las conductas de preparación, se debe proponer un sistema de cierre para evitar que se sigan «filtrando» en el Código Penal más actos de estricta preparación. A mi modo de ver, una desmesurada inclusión de conductas preparatorias no nos alejaría de limitaciones injustificadas para coartar libertades; por ello la necesidad de un micro sistema de filtro.

${ }^{26}$ Véase, entre otras, STS 323/2006, 22 de Marzo de 2006; STS 9/2017, 18 de Enero de 2017.

27 También crítico sobre este particular Juan Carlos Campo Moreno, Los actos preparatorios punibles, (Valencia: Tirant lo Blanch, 2000), 23. Quien apuesta por una restricción para esta forma de intervención. Campo Moreno afirma que para admitir dicho recurso e identificar el injusto de estas conductas habrá que entender a tres criterios fundamentales. El primero, el criterio del bien jurídico; el segundo, el criterio de la acción, esto es, la clase de conducta que amenaza con lesionar el interés social protegido; el tercer 
Penal, así como «actos preparatorios autónomos» ${ }^{28}$, demostrando un interés preponderante en la preparación delictiva como instrumento de lucha contra el crimen.

8. Si hoy asumimos a los «actos preparatorios punibles» mediante un sistema cerrado, nos preguntamos, qué es «lo que ocurre» con los «delitos de preparación». ¿Se tratan de conductas tipificadas con tentativa autónoma? ¿Son solo aquellas conductas que sancionan una inducción o cooperación psíquica independiente? ¿Se refieren únicamente a la prohibición de tenencia de útiles o instrumentos para delinquir, así como a la capacitación para cometer un delito? Varios han sido los razonamientos expresados por la doctrina, razonamientos que pasamos a analizar para luego presentar nuestra opinión.

\section{III.REVISIÓN DE ALGUNOS AUTORES}

\section{HiRSCH/WoHLERS: los «delitos de preparación» no producen un resultado lesivo}

1. Antes de presentarnos un concepto de «delitos de preparación»o «delitos preparatorios», los autores parten de una idea fundamental, recordar la función que le corresponde a la teoría del bien jurídico en el Derecho penal. Pues bien, se trata de una misión crítica frente a las decisiones que toma el legislador cuando eleva conductas a la categoría de delito, puesto aseguran que mediante dichos preceptos, «delitos de preparación», no se salva ningún interés jurídico ${ }^{29}$. Entremos en detalle. Aunque el centro de discusión para estos autores puede darse, en menor o mayor grado, en determinar si es legítimo o no adelantar las barreras de protección penal para algunos bienes jurí$\operatorname{dicos}^{30}$, también estudian la posibilidad de parámetros normativos para

criterio, se trata, pues, del respeto a los principios de intervención mínima que deberían -también a nuestro parecer-inspirar el ejercicio de la intervención penal.

${ }_{28}^{28}$ Francisco Muñoz Conde y Mercedes García Arán, Derecho penal..., 444.

29 Andrew Von Hirsch /Wolfgang Wohlers, «Teoría del bien jurídico y estructura del delito. Sobre los criterios de una imputación justa», en La teoría del bien jurídico. ¿Fundamento de legitimación del Derecho penal o juego de abalorios dogmáticos?, en trd. Beatriz Spínola Tártalo, y Roland Hefendehl/Andrew Von Hirsch/Wolfgang Wohlers edtrs., (Madrid: Marcial Pons, 2007), 287. Desde esta opinión, la legitimidad de un tipo penal se basa en analizar tanto las medidas como las formas de ataque que puede recibir un bien jurídico, puesto que la legitimación del precepto no puede hacerse -de manera exclusiva- mediante la fijación de un bien jurídico «merecedor» de tutela; por el contrario, el problema está en detallar qué clase de conductas encubren una afectación directa para el bien jurídico que se protege.

30 Andrew Von Hirsch /Wolfgang Wohlers, «Teoría del bien jurídico»..., 288. 
valorar la legitimidad en la forma que se emplea, o sea, a través de un adelantamiento que representa la ausencia tanto de lesión como de resultado.

En lo que se refiera a una descripción, aseguran que los «delitos de preparación» al no ser tipos de resultado necesariamente tendrán que incluirse en los delitos de peligro, pues se trata de una clasificación clásica y aceptada en Derecho penal. Efectivamente, resulta notorio que en la categoría de delitos de peligro abstracto podrían entran - por así decirlo- todo aquel precepto que no pueda ser calificado como tipo de resultado o, en su desperfecto, como de delito de peligro concreto. De modo que los «delitos de preparación»siguiendo a HIRSCH y a WOHLERS- deben quedar incluidos dentro de los delitos de peligro abstracto; pues son delitos cuyo ámbito de protección consiste en salvar tanto bienes jurídicos personales como colectivos sin que se requiera la lesión para dicho bien jurídico.

Mediante esta técnica, afirman los autores, se sancionan conductas que por sí solas son incapaces de producir un resultado lesivo, pero pueden servir de plataforma para la comisión de una infracción penal. Al respecto, exponen algunos ejemplos, pero siempre relacionados a la posesión; «posesión de sustancias peligrosas». Sobre este particular, es evidente que la mera tenencia de un veneno $u$ otra sustancia no pueden generar una lesión -por si sola-para la vida o para la integridad física de las personas, pues hace falta que «alguien haga algo más. No obstante, si se utiliza o se da inicio a un proyecto criminal, concluyente, mediante su uso, no podemos negar que se organiza un riesgo de lesión, a pesar de que ex ante la mera tenencia resultare inofensiva. En otro orden de ideas, también comentan la necesidad de elaborar un conjunto de presupuesto para admitir esta forma de adelantamiento, que como se dijo en su momento, el problema no está tanto en el objeto de protección, que aunque digno de adelantamiento también debemos centrarnos en la forma de anticipación. Desde mi parecer, para admitir o legitimar los «delitos de preparación» será indispensable contar con unos requisitos que sirvan de límite para esta técnica de intervención. Como se mencionó, pese a proteger intereses sociales importantes, de los que casi nadie niega su reconocimiento, son preceptos que no presentan ni un resultado lesivo («daño») ni una ejecución $(« \text { conducta») })^{31}$.

${ }^{31}$ El hecho de que el legislador incluya mediante este método de protección varios bienes jurídicos no quiere decir que todo reforzamiento de protección ha de ser cuestionable, es decir, que debamos dudar de la importancia del interés protegido. Creo que allí no se encuentra el tema de debate; por el contrario, considero que el debate se encuentra en el criterio de selección de esos bienes, porque a efectos de preparación delictiva poco importa la sobreprotección. Vamos a una comparación, no es lo mismo adelantar la protección para un interés de menor entidad que para un bien jurídico indispensable, por caso, la vida huma. Pues cuando hablamos de ese bien, lo entendemos como un valor de 


\section{KUBLEN: un injusto mayor obedece a una lesión concreta}

Por lo que alcanzo a ver, este autor, inicia sus críticas al revisar los «delitos de preparación» a partir del grado de cercanía (o «posible») lesión del bien jurídico. Discute tanto el nivel como el merecimiento de la pena que habrá de fijar el legislador. Kublen ${ }^{32}$ asegura que un injusto mayor obedece a una lesión concreta, o sea, cuando percibimos una lesión «real», es decir, una lesión «seria» que afecta de manera directa a un interés jurídico protegido, perturbando a la convivencia (se refiere a un resultado en sentido fenoménico).

Hasta aquí se podrían plantear algunas valoraciones, remitiéndonos a los limitantes que se le impone a un Estado de Derecho de cara al ejercicio de su potestad punitiva ${ }^{33}$. Esto nos remitiría, cuanto menos, al principio de proporcionalidad, pero también al de lesión. En ese sentido -continuando con Kublen- nadie pone en duda que el legislador cuenta con la potestad de determinar lo que ha de ser delito, además, pude acudir y acude a las figuras que mejor le parezca, o sea, estipula cuál es de mayor utilidad o cuál es de mejor eficacia para garantizar la convivencia de los individuos en una determinada sociedad. Y, por eso, puede fijar medidas que restringen la libertad mediante la prohibición de una lesión o, lo que podría resultar más «drástico», sancionar una mera probabilidad, una puesta en peligro o una serie de actos de estricta preparación. Pues bien, este autor nos dirige al término de un análisis que contiene aspectos tanto normativos como doctrinales al afirmar

indiscutible prelación, esto es, máximo, irrefutable...; lo mismo se podría decir de la integridad sexual; mucho más si se trata de un menor. En virtud de que en el ámbito sexual se relacionan y se protegen intereses insalvables, irrecuperables; además, entra en juego la incapacidad del titular del bien. De suerte que se hace razonable adjudicarle un grado (o un nivel) de adelantamiento a razón de su inferioridad, de su indefensión, por eso es indiscutible la necesidad de entender al interés protegido. Creo que estas apreciaciones pueden introducirnos -aunque sea en menor medida- a la elaboración de criterios de selección para restringir el poder punitivo en materia de «delitos de preparación» en el Código Penal. Hasta este punto, podemos decir que tanto el bien jurídico como el titular del mismo han de ser considerados al momento de emplear los «delitos de preparación» como recurso de adelantamiento.

${ }^{32}$ Lotbar Kublen, «Bienes Jurídicos y nuevos tipos de delito», en Límites al Derecho penal. Principios operativos en la fundamentación del castigo, edit. Por Andrew von Hirsch/Kurt Seelmann/Wolfgang Wohlers (Barcelona: Atelier, 2012), 225-229.

${ }^{33}$ Francisco Muñoz Conde y Mercedes García Arán, Derecho penal..., 89-90: «La intervención del Derecho penal en la protección de bienes jurídicos dependerá además, como dice Hassermer, del criterio de merecimiento de pena, es decir, del juicio de si un comportamiento concreto que afecte a un determinado bien jurídico debe, por la gravedad del ataque, por la propia importancia del bien jurídico, etc., ser sancionado penalmente» (cursivas en original). 
que: «Normativamente $[\ldots]$ no es legítimo crear tipos penales que vayan más allá del peligro abstracto», pero -en palabras del propio Kublen- «la discusión más reciente a esta suposición se ha modificado y reducido de forma tan significativa que también podría decirse que ha sido rechazada» ${ }^{34}$.

Los «delitos de preparación» para KUBLEN buscan expandir la responsabilidad penal, tipificando conductas que no representan una lesión a un bien jurídico. Aunque hablando en términos normativos, estas figuras sí que sirven de base perfecta para la realización de otro tipo pena ${ }^{35}$. Los separa tanto de los delitos de peligro abstracto como de los delitos de acumulación y nos brinda un par de ejemplos. El primero, fabricación de moneda falsa; el segundo, venta de armas de fuego. Además, asegura que su legitimidad no puede ser objeto de discusión, del mismo modo afirma que esta clase de delitos merecen ser incluidos en una «ulterior categoría delictiva».

Comparto la postura de Kublen en cuanto a la descripción ofrecida para estos preceptos, igualmente, participo en la valoración del injusto que nos brinda en su contribución. En efecto, también comparto el carácter «formal» que aprecia en los «delitos de preparación», pues entiendo que sirven para cometer otro delito. Sin embargo, no estoy totalmente de acuerdo con que estas figuras no puedan ser objeto de discusión de cara a su legitimidad-que es lo que Kublen también sostiene-, dado que los tipos penales que sanciona la preparación presentan incongruencias dogmáticas, son normas penales que rompen los esquemas tradicionales de imputación y ponen en tela de juicio el mantenimiento de no pocos principios básicos del Derecho penal. La apreciación del injusto en esas normas penales se dirige, más que a otro lugar, a estadios de eficacia preventiva, ubicándonos en un Derecho penal de excesos, puesto que no permiten determinar, en muchos supuestos, ni siquiera, el inicio de un proyecto delictivo concreto.

\section{PUCHKE: los «delitos de preparación» buscan quitarle al futuro autor el dominio del hecho}

Este autor relaciona la inclusión de los «delitos de preparación» con la necesidad de afrontar los retos de vivir en una sociedad de riesgo, sociedad que percibe cierta amenaza en casi todo su entorno; esto es: la salud, el medio ambiente, el empleo, etc. Con no menor conducencia sostiene PuCHKE que los «delitos de preparación» representan el inicio de un nuevo Derecho penal

${ }^{34}$ Lotbar Kublen, «Bienes Jurídicos y nuevos tipos de delito», 226.

35 Al brindar una descripción para estos tipos afirma que: «Lo que en ellos resulta decisivo es que ofrecen un punto de partida normativamente suficiente para las posteriores conductas delictivas del autor y otras personas», Lotbar Kublen, «Bienes Jurídicos y nuevos tipos de delito», 229. 
que se centra en evitar la producción de posibles acciones delictivas, pero siempre enfocadas en el futuro ${ }^{36}$.

Efectivamente, cobra sentido cuando afirma que no es legítimo considerar a las actitudes delictivas como elemento objetivo típico, puesto que estas por si solas- no representan nunca ninguna clase de peligro para un bien jurídico que impida la convivencia.

En palabras de Puschke: «Un Derecho penal del hecho orientado al bien jurídico, respetuoso del principio constitucional nullum crimen sine legen y con un mandato de determinación, exige además, una conducta establecida propiamente cargada de significado que produzca la puesta en peligro de un bien jurídico en términos objetivos $»{ }^{37}$. Podríamos continuar con más apreciaciones de este nivel, pero por de pronto, pasaremos a centrarnos en algunos aspectos relacionados con la legitimidad de los «delitos de preparación».

Para empezar, se refiere a ellos mediante el término «tipos penales que elevan actos preparatorios a la categoría de delito». Sabemos que nos encontramos ante meras consideraciones, puesto que el legislador equipara la preparación delictiva con la realización perfecta dolosa en términos penológicos en varios supuestos. En efecto, entendemos que el legislador es consciente de romper el significado conceptual que envuelven a estas normas penales, lo que es: conoce que se trata de una consideración ajena al lenguaje ordinario y que quiebra la representación conceptual del injusto penal. Volviendo al autor, Puschke asegura que estos tipos deben incluirse dentro del grupo de los de los «delitos de peligro abstracto». Sostiene son preceptos orientados a una acción lesiva que se conseguirá en un ulterior momento, de suerte que no se puede determinar la lesión de un interés protegido. Sin embargo, son empleados para reforzar la protección de bienes sociales tanto individuales como colectivos.

A nuestro juicio -aunque leyendo a Puschke-no es necesario hablar de cierta gravedad en términos de valores de protección para poder acudir a esta figura, lo cierto es que se protege tanto la vida como la propiedad intelectual mediante una misma técnica que corta la correspondencia subjetiva con la afectación objetiva del bien jurídico protegido. Lo que pretende entonces el legislador mediante la inclusión de estas normas penales, es tratar de quitarle al criminal el dominio de un hecho que se producirá o que puede producirse en el futuro.

Por último, este autor argumenta que los «tipos penales que elevan actos preparatorios a la categoría de delito» tienen «cinco piedras de toque» ${ }^{38}$. En

36 Jens Puschke, «Origen, esencia y límites de los tipos penales que elevan actos preparatorios a la categoría de delito», Indret Penal 4 (2010), 9.

37 Jens Puschke, «Origen, esencia y límites», 18.

38 Jens Puschke, «Origen, esencia y límites», 13: «En relación con los límites de la legitimidad de tipos penales que tipifican actos preparatorios cabe hablar de cinco piedras 
nuestras palabras: son normas indeterminadas, se centran en el ámbito de la autonomía de las personas, tanto las penas como las conductas tipificadas no responden a la proporcionalidad penal y los intereses que se intentan proteger no son todos merecedores de esta protección. Por eso, a mi modo de ver, es necesario proponer criterio que restrinjan la inclusión de esta categoría delictiva en nuestro Código Penal.

\section{BARBER BURUSCO: los «delitos de preparación» están dirigidos a evitar la preparación de otro delito}

Esta autora se destaca, entre otras investigaciones, por haber aportado a la doctrina española una valiosa interpretación, así como un serio estudio respecto a los asuntos más problemáticos que presentan los «actos preparatorios punibles»: su legitimación. Los describe como una de las formas de preparación delictiva, en efecto, dentro de su ámbito de estudio incluye a los «delitos de preparación» como otra forma de preparación punible. Los denomina «delitos de preparación» o «actos preparatorios elevados a la categoría de delito autónomo ${ }^{39} \gg$. Afirma que la razón de ser de este instrumento de anticipación no radica en la protección de un bien jurídico, sino en conductas encaminadas o dirigidas a preparar otro delito ${ }^{40}$. Entiendo que dicha particularidad es lo que capta la atención del legislador, puesto que se centra en la prohibición de acciones que si bien no han alcanzado siquiera el inicio de una actividad peligrosa; ello no es un obstáculo como para establecer un castigo. En otras palabras, se pretende evitar algo que con cierto grado de certeza podría llegar a producirse.

A partir del panorama descrito por la autora se podrían presentar-cuanto menos- dos problemas. El primero, la lejanía del bien jurídico «susceptible de afectación». El segundo, los inconvenientes en determinar la «conducta típica», esto es, fijar qué clase de contactas podría crear un riesgo típicamente relevante a la luz de estos preceptos. Siguiendo el análisis y las

de toque que adquieren especial relevancia: En primer lugar, los efectos del Derecho penal han de producirse en la esfera psicológica -y no exclusivamente a través de la intervención-, también en los tipos penales que recogen actos preparatorios. En segundo lugar, el objeto de protección de estos tipos penales sólo puede ser un bien jurídico concreto con un contenido estrechamente delimitado. En tercer lugar, sólo el castigo de conductas preparatorias peligrosas, es decir, conductas típicas con una concreta intención de lesionar, resulta acorde con el principio de proporcionalidad. En cuarto lugar, las conductas incriminadas no pueden pertenecer al ámbito de autonomía del sujeto. Por último, las normas tienen que ser concretas, de manera que respeten el principio de determinación».

39 Soledad Barber Burusco, Los actos preparatorios del delito: Conspiración, proposición y provocación, (Comenares: Granada, 2004), 148.

40 Soledad Barber Burusco, Los actos preparatorios..., 152-153. 
particularidades comentadas, también sobresalen una serie de contradicciones. Vamos a resaltar algunas de ellas. Por una parte, se estima una clara contradicción con el principio de igualdad ${ }^{41}$; por otra parte, se percibe una vulneración de cara a lo que entendemos por el principio de eficacia penal ${ }^{42}$. La primera, se centra en el análisis comparativo con relación a los «actos preparatorios punibles», pues no está de acuerdo en que se fije para esta forma de preparación delictiva la misma pena prevista para los tipos de tentativa. Desde nuestro puno de vista este planteamiento resulta correcto, ya que la gravedad de la tentativa, para algunos, está en el inicio de un proyecto criminal que no se produce por causas que escapan de la voluntad del autor, pero que a razón del mensaje que lanza en autor de la tentativa o de las consecuencias producidas y otros motivos relacionados nos decantamos por admitir la sanción. Pueda que se llegue a lesionar un bien jurídico después de la preparación de un ilícito, y que por eso se anticipe la intervención, por fines meramente preventivos; sin embargo, la tentativa resulta más grave que la preparación ${ }^{43}$.

Así las cosas, creo que también faltaría al principio de igualdad a partir de este análisis. Si admitimos sancionar la mera preparación de conductas encaminadas a cometer un delito, pero no con una pena acorde al grado de lesión, sino con una igual a la del resultado del respectivo tipo fin... En mi opinión, considero que esta decisión legislativa no encaja en lo que entendemos por igualdad ${ }^{44}$.

41 Soledad Barber Burusco, Los actos preparatorios..., 118.

42 Soledad Barber Burusco, Los actos preparatorios ..., 119-120.

43 Véase, STS 109/2017, 22 de Febrero de 2017.

${ }_{44}$ Son dos los argumentos que presento respecto al criterio de igualdad. Por un lado, no sería correcto sancionar con la misma pena tanto actos preparatorios como la realización perfecta de un delito base, puesto que las conductas preparatorias no logran afectar la estabilidad del bien jurídico: no hay ni siquiera inicio. Por otro lado, podemos añadir, que en virtud de estas circunstancias, resultaría más igualitario intentar una conducta, si bien no se consiga, que prepararla. No pocos casos sostienen esta afirmación, véase, entre otros, la pena descrita en los siguientes preceptos: 270.6, 286.1, 345, 371.1, 386.2, 399 bis, 400, 563. Mediante estos tipos, el legalismo eleva a la categoría de delito actos de estricta preparación, incluyendo sanciones desiguales.

Nótese que la pena que se prevé para la tentativa es inferior que la prevista en la preparación a pesar de que en esta última no se dé inicio a la ejecución. De modo que la lógica legislativa podría estar en las siguientes líneas, entre menos acciones criminales se realicen, a pesar de que la posible lesión del bien jurídico esté más distante, la condena será mayor (pena equiparada al resultado). Y entre más conductas se ejecuten, buscando la consumación del resultado, aunque no se consigan pese haberse iniciado, la pena será menor (pena de tentativa). Entre más lejos estenos del resultado, tendremos más sanción (pena de preparación). 
A partir de la crítica de Barber, entendemos que en términos penológicos resultaría más conveniente al delincuente intentar el delito (es decir, dar inicio a la ejecución del hecho directamente por hechos exteriores...) que «entrar en la preparación delictiva», lo que resultaría un ámbito más peligroso de lo que parece para el delincuente. A todo esto, podemos cuestionarnos la misión que le corresponde al Derecho Penal, en concreto, determinar si este instrumento está llamado a resolver las vicisitudes que se relacionan con los delitos de preparación. En todo caso, Barber afirma que no es competencia del Derecho Penal tratar de resolver los asuntos que se involucran tras la inclusión de estos tipos, puesto que el Derecho Penal carece de capacidad como para intervenir («eficazmente») en todos los supuestos que maquinan actividades delictivas; y con razón, pues ello resultaría una competencia absolutamente inabarcable ${ }^{45}$.

\section{CorCoy BidASOlo: los «delitos de preparación» sólo podrían justificarse por el bien jurídico protegido}

Los denomina «actos preparatorios como delitos de peligro». Advierte que su legitimidad dependerá, únicamente, de la relevancia del bien jurídico que se quiera proteger. Conjuntamente, la preparación debe implicar ciertas actividades de peligro donde se evidencie un incremento relevante del riesgo permitido ${ }^{46}$. Cita algunos ejemplos como la fabricación, recepción, obtención o tenencia de útiles, materiales, instrumentos, sustancias... para cometer el delito de falsedades (art. 400) ${ }^{47}$; así como el antiguo art. 509 del Código Penal de 1973, respecto a este último ofrece una interesante reflexión.

Los «delitos de preparación» se pueden clasificar, según Corcoy, mediante dos posibles grupos. Por un lado estarían los «delitos de preparación de peligro abstracto», por otro lado, los «actos preparatorios autónomos». Sobre los primeros advierte que estarían legitimados si se equipara al delito de tenencia de armas o sin licencias, pese a la necesidad de demostrar el incremento del riesgo. Sobre los segundos, señala que no podrían estar legitimados de ninguna manera atendiendo al siguiente argumento: «Si, como vimos, la punición de la tentativa de delitos de peligro abstracto no está legitimada, menos lo pueden estar los actos preparatorios.... ${ }^{48}$.

${ }^{45}$ Soledad Barber Burusco, Los actos preparatorios..., 120: «El principio de eficacia queda altamente cuestionado. Pues en principio no parece posible (ni deseable) que las instituciones penales tengan la capacidad de intervenir en todos o al menos en un número importante de supuestos en los que se proyecten cualquier clase de hechos delictivos»».

46 STS 19 de noviembre de 2014 (MP: Manuel Marchena Gómez 771/2014), F.D. 2.

47 Mirentxu Corcoy Bidasolo, Delitos de peligro..., 284.

48 Mirentxu Corcoy Bidasolo, Delitos de peligro..., 284. 
De cara a la segunda clasificación, esto es, «actos preparatorios autónomos», nos recuerda que en su momento fueron considerados como delitos de sospecha, puesto que no era necesario probar que las conductas tildadas por el legislador como preparatorias estaban destinadas a la comisión de un delito, sino se daba por seguro. Pues bien, se trata de conductas de las que se presume la realización de un ilícito penal, aunque se ausente el inicio del plan delictivo.

Pero además, advierte que la tipificación de actos preparatorios como delito autónomo pude terminar en la incriminación de sujetos que no han planeado nunca la posibilidad de cometer una infracción penal o participar en ella, infringiendo el principio de culpabilidad personal, este método de anticipación es capaz de llegar a espacios inimaginables ${ }^{49}$. Del mismo modo, son delitos que dificultan o, de otro modo, imposibilitan la diferenciación entre actos de preparación y actos de consumación.

\section{IV.UNIÓN DE SUJETOS EN LOS «ACTOS PREPARATORIOS PUNIBLES»Y SUS CONSECUENCIAS DOGMÁTICAS}

El hecho de que varias personas se unan para realizar un objetivo o un proyecto determinado, generalmente, incrementa las posibilidades para su obtención. Conjuntamente, puede entenderse que la inclusión de más personas en los «actos preparatorios punibles» implica la imposibilidad de «desistir voluntariamente» del proyecto criminal, pues obvio que se pierde el poder de controlar la circunstancia criminal.

Casi nadie discute que la unión de sujetos agrava el injusto debido al incremento potencial que representa el concurso de persona que libremente deciden cometer un delito. Ahora bien, aunque dicho incremento no esté presente en los «delitos de preparación», es un elemento clave en los «actos preparatorios punibles». Esto nos demuestra que no es un requisito utilizado por el legislador penal para admitir el adelantamiento que caracteriza a los «delitos de preparación». También, como se adelantó, resulta discutible determinar cómo se podrá adjudicar el incentivo o premio para sujetos que quieran desistir en la preparación delictiva respecto a los «delitos de preparación». Por eso, pasamos a analizar dos puntos (hipotéticos) de cara a la importancia del desistimiento voluntario en la preparación delictiva. El primer punto, si la teoría del premio está pensada en recompensar al criminal que se arrepiente, entendemos que si el legislador introduce tipos penales con difícil determinación de dicha figura es porque («posiblemente») estima que tales conductas representan una magnitud tan relevante -en términos de

${ }^{49}$ En ese sentido, como adelantamos, entraría en juego su incompatibilidad con el principio de culpabilidad. Esto es, nadie puede responder por la acción criminal ejecutada por otro (responsabilidad personal). 
peligrosidad- que no merecen la adjudicación del perdón por parte del Estado. Si esto es así, es decir, si el criterio de gravedad es lo que invita al legislador a crear figuras que resulta complejo la adjudicación de la recompensa, podríamos suponer otra contradicción por parte del legislador. Es complejo determinar la prerrogativa del desistimiento en los «delitos de preparación» porque se adelanta la barrera de sanción a un paso previo a la tentativa sin que se produzca una lesión al bien jurídico ${ }^{50}$; de ese modo, la compleja determinación de la conducta jurídicamente relevante, a efectos de preparación, quedaría absorbida en el análisis de la consumación del tipo objetivo. Por otro lado, si la teoría del premio busca enviar un mensaje de ejemplaridad que exprese que «la ley sabe» galardonar a los arrepentidos, tampoco encajaría dicho mensaje porque mediante los «delitos de preparación» resulta difícil evitar la consunción, pues como hemos visto, se habla de desistir de una ejecución iniciada y aquí se sanciona la preparación ${ }^{51}$. De ese modo, un sujeto podría desistir, voluntariamente, cuando después de empezar la instalación del arsenal; desecha el conjunto de materiales absolutamente idóneos para la creación de billetes falsos (art. $400 \mathrm{CP})^{52}$. Nótese que en el supuesto apuntado, el acto de desistir se encuentra inmerso en espacios de la intimidad del individuo que no logran aún la puesta en marcha de un peligro remoto.

En cuanto al principio de igualdad, hemos anunciado que con los «delitos de preparación» el legislador aplica una pena superior a la prevista en la tentativa del respectivo delito fin, así como otras sanciones desmedidas, también sabemos que acude a una pena igual a la señalada en el delito base, a pesar de tipificar actos de mera «elaboración»" ${ }^{53}$. De ese modo, la lógica (o la coherencia) legislativa se ve quebrantada y el mensaje que pretenda enviar mediante estos preceptos se torna mucho más incomprensible ${ }^{54}$.

Ante lo expuesto, cabe recordar que solo es posible el desistimiento voluntario en aquellos tipos que admiten la tentativa, dado que el desistimiento voluntario se encuentra inmerso en dicha figura (art. $16 \mathrm{CP}$ ).

A pesar de que la inclusión de otros sujetos en un determinado proyecto sirva de fundamento para adelantar la intervención penal como es el caso de

${ }^{50}$ Francisco Muñoz Conde y Mercedes García Arán, Derecho Penal..., 448-451; Esteban Sola Recha, La llamada tentativa inidónea del delito. Aspectos básicos, (Granada: Comares, 1996), 74-75; entre otros.

${ }^{51}$ De otra opinión, Marcelo Domínguez Correa, El desistimiento de la tentativa, (Buenos Aires/Montevideo: BdF, 2013), 114-145.

52 Véase, STS 771/2014, 19 de Noviembre de 2014.

${ }_{53}$ Véase, por ejemplo, la sanción prevista para las siguientes: arts. 557.2, 559, 576, $577 ; 249,428,475$ y 575.2 .

${ }^{54}$ En similar sentido, entre otros, SAP Burgos 69/2014, 21 de Febrero de 2014. 
los «actos preparatorios punibles», el legislador ha dejado claro que dicha inclusión no es necesaria para la tipificación de «delitos de preparación». Además, el criterio de inclusión no parece responder a la naturaleza de los «delitos de preparación»; no obstante, como lo mencionamos, la necesidad de incluir a otros en un programa delictivo, muy a pesar de la importancia representada, es desestimado para unas figuras («actos preparatorios autónomos»); pero apreciado en otras («actos preparatorios punibles»).

Lo anterior nos aproxima cada vez más a la idea de que los «delitos de preparación» representan otra clase de riesgo en comparación con figuras que necesiten la inclusión de dos o más sujetos para configurar la legitimidad del adelantamiento. Así pues, aunque es notable el incremento de peligro cuando dos o más sujetos se juntan para delinquir, lo cierto es que existen figuras referidas a la preparación delictiva que no necesitan de ninguna clase de concierto para ser elevadas a la categoría de delito y que objetivamente se ubican en un estadio anterior a la tentativa y representa un grado de peligrosidad distinto a los propios «actos preparatorios punibles».

\section{LA POSTURA JURISPRUDENCIAL}

Expuestas varias nociones respecto a los «delitos de preparación», vamos a analizar algunos criterios aportados por la doctrina jurisprudencial relacionados con el adelantamiento a de la intervención penal. Pues bien, veremos cuáles son los motivos que tienen en cuenta los tribunales respecto a la sanción de estadios de estricta preparación. A todo esto, si el Código Penal de 1995 se decantó por no castigar de manera general ningún acto preparatorio $^{55}$, posiblemente en dicha decisión se encubren algunos motivos, por el hecho de referirnos a la excepción del castigo de conductas en estado de preparación ${ }^{56}$. Volviendo al tema de la doctrina Jurisprudencial, pasamos a señalar dos consideraciones.

En primer lugar, el Tribunal Supremo ${ }^{57}$, con ocasión a la forma de emplear los instrumentos que anticipan la intervención penal entiende que ha de admitirse la «infracción» a los principios limitadores del poder punitivo a razón de la importancia del bien jurídico objeto de protección, eso es lo que permite o justifica el adelantamiento, aunque resulte un poco desmesurado; pues hay situaciones en que desde el estado de preparación se aprecia una peligrosidad inminente para el bien jurídico objeto de protección. Así, a este respecto, el Tribunal se refiere, puntualmente, al fenómeno del terrorismo, pues tanto la vida como la seguridad de las personas, así como la paz social

\footnotetext{
55 Santiago Mir Puig, Derecho penal ..., p. 350.

56 Véase, STS 177/2018, 12 de Abril de 2018.

57 STS 1993/1189, 8 de Marzo de 1995.
} 
estarían «en juego» ${ }^{58}$. También, nos ha recordado el Tribunal que los actos de preparación no pasan a la fase de ejecución, pero como advierte la Sentencia: «La prevalencia de los bienes jurídicos obligan a anticipar la barrera de protección penal».

En segundo lugar, el Tribunal Constitucional admite que no se ve vulnerado el principio de proporcionalidad en un adelantamiento de intervención siempre y cuando el bien jurídico sea de primer nivel, por lo que deben estar relacionadas conductas que impliquen una amplísima valoración social. En definitiva, se refiere a que la intervención, en términos de preparación, es proporcional por considerarse un medio necesario para salvar dichos interés que se aprecian como merecedores de un adelantamiento.

A partir de ese panorama, si tanto el bien jurídico como la gravedad representada en la formación del ataque se utilizan para calificar un adelantamiento como justificado y proporcional, no encontramos razones que impidan que en los «delitos de preparación» sea necesario acudir a criterios que transiten en esta dirección. Más cuando representan una mayor lejanía tanto en términos de puesta en peligro como de lesión, si los comparamos con otras figuras de anticipación ${ }^{59}$.

La utilización de esos elementos son -hasta el momento- requisitos esenciales empleados por la Jurisprudencia para interpretar la preparación delicita que caracteriza a los «actos preparatorios punibles». Asimismo, podemos decir que los criterios son congruentes, hasta cierto punto, con las posiciones doctrinales que hemos repasado en este trabajo ${ }^{60}$.

\section{VI.SOBRE LA ATENUACIÓN OBLIGATORIA DE LA PENA EN LOS «DELITOS DE PREPARACIÓN»}

1. Algunos autores conciben que, más que buscar nuevos criterios para regular los delitos de preparación habría que evitar la desproporcionalidad de esas normas y otros problemas derogando un gran número de preceptos ${ }^{61}$. Otra salida podría se otorgarle al juez la potestad de imponer al autor de la preparación en supuestos graves la pena inferior en un grado a la señalada para el delito que prepara. En definitiva, lo que se trata es de proponer otro marco penal que atienda al criterio preventivo general más allá de optar por la exclusión de estas figuras de facto.

58 Véase también, STS 214/2018, 8 de Mayo de 2018.

59 Véase, STS 149/2017, 9 de Marzo de 2017.

${ }^{60}$ Santiago Mir Puig, Derecho penal ..., p. 350.

${ }^{61}$ De esta opinión, Alberto Alonso Rimo, «Los nuevos delitos de ¿desórdenes? ¿públicos? Especial referencia a los tipos de incitación o de refuerzo de la disposición a delinquir (art. 557.2 y 559 CP)», Estudios Penales y Criminológicos, 35 (2015), 371. 
No obstante, dado el caso de que la crítica que recibiría esta propuesta fuera la inseguridad jurídica procedente de la actual situación, esto es, por la proliferación de «delitos de preparación» en el Código Penal, no encontramos motivos para estimar razonable transformar esa inseguridad en una completa libertad del juez, despojando además de esta forma la calificación jurídica de la conducta al control judicial previsto en la casación. Por otro lado, con la disminución de la pena prevista en los preceptos referidos a «delitos de preparación» no se soluciona el problema, sino que simplemente se reduciría. Con ello, obviamente se disminuiría la cuestión, por lo que solo dilataría la necesidad de limitar algunas cuestiones como las implicadas en la calificación de conductas como principales («delimitación de autoría»), secundarias («delimitación de la participación»), así como en el inicio de la tentativa, en la accesoriedad cualitativa, etc.

Al estudiar estas figuras encontramos que no hay, todavía, razones suficientes como para defender una inmediata derogación de todos los preceptos referidos a los «delitos de preparación». Pues existen motivos como la inseguridad en algunos ámbitos relacionados con la tecnología que dan lugar a la permanencia de algunos preceptos en el Código Penal.

En otro orden de ideas, si la limitación es entendida como un recurso basado en la interpretación restrictiva, entendemos que no es del todo conveniente por la misma vaguedad de su contenido. Por eso, tanto a la doctrina como a la Jurisprudencia le corresponde proponer criterios limitadores que se ajusten a los principios básicos del Derecho Penal; en similar dirección, si existen dudas para la imputación de un precepto como «delito de preparación», creo que a nadie se le ocurriría negar la aplicabilidad del principio in dubio pro reo.

Por descontado, atendiendo a la función del Derecho penal que hemos mantenido, esto es, como instrumento de control social, creo que no deberían ser valoradas conductas con posibilidad de un resultado o aquellas que solo incrementan el riesgo de posibilidad de lesión sin que implique de por sí una lesión, no es un postura que se distancie de los criterios empleados por la doctrina Jurisprudencial.

Tanto la disminución obligada de la pena prevista actualmente para los «delitos de preparación» como la restricción de elevar a la categoría de delito meros aspectos de preparación, se basa en la falta de relevancia; pues carecemos de certeza respecto de la producción del resultado... Además, el propio Código Penal establece el límite mínimo para sancionar conductas (art. $10 \mathrm{CP}$ ).

La propuesta de sancionar los «delitos de preparación» con una pena inferior, cobra sentido cuando al centrarnos en una figura que rompe la lógica interna del legislador ${ }^{62}$. La doctrina asegura que en los «actos preparatorios

${ }^{62}$ Véase, STS 660/2018, 17 de Diciembre de 2018. 
punibles» no caben las formas de imperfecta realización, así, es el mismo Mir Puig quien asegura que: «Como nos hallamos frente a «delitos no autónomos»), no cabe en ellos la participación ni la punción de formas de imperfecta realización ${ }^{63}$. Pues bien, cabría preguntarse por qué en los actos preparatorios punibles no pueden involucrarse las reglas de la participación o de la tentativa... La razón consiste en que ellos no son delitos y que dichas reglas sólo son aplicables para tipos autónomos previstos en la Parte Especial, sin más. No obstante, esto no se podría predicar -al menos rápidamente- respecto a los «delitos de preparación», puesto que son tipos autónomos, en virtud de estar previstos en la Parte Especial del Código Penal. A lo que vamos, si fijamos límites reducimos el ámbito de prohibición; más aún cuando nos queda claro que la extensión de la responsabilidad criminal en los «delitos de preparación» es mucho más amplia que la representada en los «actos preparatorios punibles».

Nuevamente la lógica del legislador queda en tela de juicio. Veamos el motivo. Por un lado, nos dice que existe una «excepción» ${ }^{64}$ para el castigo de conductas de estricta preparación; pero por otro lado, incluye actos preparatorios autónomos en la Parte Especial del Código Penal. Así pues, los «delitos de preparación» no encajan con la conocida excepción para el castigo de conductas de estricta preparación, pues se caracterizan -como se ha reiterado en este trabajo- no solo por ampliar desmesuradamente la responsabilidad penal, también, por señalar un castigo desmesurado respecto al peligro que representan.

La necesaria disminución de la pena para estas normas penales, en todo caso, es una cuestión de lege ferenda que aportaría a eliminar el tratamiento arbitrio que realiza el legislador penal al incluir paulatinamente conductas de preparación sin explicar «el por qué» de su inclusión y «el cómo» de su aplicación, más allá de asumir compromisos internacionales en algunos casos que sugieren u obligan a garantizar la armonía en ciertos ámbitos de la sociedad. Esto a nuestro modo de ver es necesario, pues contradice la denominada excepción para el castigo de conductas en estado de preparación en la legislación penal.

Seguidamente, pretendemos analizar por qué es lógico rebajar la pena en los «delitos de preparación» como figuras de anticipación. Pues bien, la diferencia entre la preparación y la consumación de un ilícito penal, en términos de sanción, debería entenderse como una garantía que emana del principio de proporcionalidad. La preparación debe ser moderada, proporcionalmente menor respecto al delito doloso consumado (o intentado).

63 Santiago Mir Puig, Derecho Penal..., 351.
64 Véase, STS 428/2016, 19 de Mayo de 2016. 
Una propuesta de menor sanción para los «delitos de preparación» no depende de su tipificación como delitos siu generis. Pasaré a desarrollar esta valoración. Entre la preparación delictiva y la consumación media una distinción en términos de gravedad, de suerte que los hechos tipificados deban llevar consigo sanciones mucho más leves respecto a los supuestos de delitos consumado (me refiero a la realización perfecta del respectivo tipo base o delito fin, esto es, la infracción penal que el sujeto prepara). En otras palabras, el castigo previsto en la preparación delictiva debe ser siempre menor que el señalado en casos de perfecta realización de delito base o tipo fin, dado que su gravedad es inferior... Esta idea tiene un soporte histórico, legislativo y sociológico. Por razones históricas, sancionar la tentativa -situándose en una fase previa a la preparación, por ejemplo- trae una conjetura antigua de castigo que caracteriza a una pena «extraordinaria», lo que es, distinta respecto a la del delito consumado doloso, de manera que nos conduce camino a la atenuación. A la par, por motivos legislativos, la previsión de la responsabilidad criminal por actos de estricta preparación se entiende como excepcional respecto a los supuestos consumados (dolosos), de modo que es obligatoria su permanente comparación y nos llevarían a admitir una sanción necesariamente menor; por tanto, el castigo no puede ser igual al de un tipo consumado ni al de una tentativa acabada porque fenoménicamente tanto los hechos como las consecuencias son distintas. Y, por razones sociológicas, podemos entender que la tipificación de conductas de estricta preparación es algo que se torna necesario, porque un relevante número de supuesto se interrelacionan con el núcleo duro de la vida ordinaria, es más, son las consecuencias o el precio de vivir en la sociedad moderna, esto es, donde la vida resulta inimaginable fuera de las fuentes de peligro (impresoras, ordenadores, máquinas fotocopiadoras, el uso del Internet.... No obstante, socialmente aceptamos que la incriminación de conductas de preparación están ubicadas en un plano excepcional y su sanción es proporcional a la gravedad que representa, por tanto, suelen caracterizarse por presentar penas inferiores a la prevista en la realización perfecta del tipo doloso porque el daño, si es que puede ser cuantificable, será siempre ínfimo en comparación con el representado en el tipo base o delito fin ${ }^{65}$.

Con todo, casi nadie dudaría que las razones citadas le resultan escasas al legislador penal. Por un lado, la historia, hasta ahora, demuestra que varias legislaciones renuncian de manera paulatinamente a los principios limitadores poder punitivo. Por otro lado, en el ámbito legislativo, no podemos olvidar que aunque se predique un criterio de «excepcionalidad», lo que es,

${ }^{65}$ Véase, entre otras, STS, 1 de Julio de 2013; STS 849/2013, 12 de Noviembre de 2013; STS 689/2014, 21 de Octubre de 2014; STS 849/2013, 12 de Noviembre de 2013; TS 174/2015, 14 de Mayo de 2015. 
sancionar «únicamente» los actos «preparatorios punibles» como ejemplo de intervención en estadio de la preparación, vemos que nuestro legislador ha demostrado otra posición. Por si fuera poco, sabemos que los «delitos de preparación» prohíben conductas que no se refieren de manera exclusiva a intereses jurídicos irrecuperables, por tanto, es tanto ilógico como innecesario que la reacción penal sea superior a la de un hecho consumado. Y, en el ámbito sociológico, no es posible pretender que valoraciones subjetivas alcancen un estatus generalizado, es decir, que puedan lograr una posición de carácter irrefutable respecto a toda una sociedad, pues los criterios personales son controvertidos y más si nos referimos a la percepción de riesgos o sensación de inseguridad: casi nadie duda de que las sensaciones personales son graduables.

Los motivos que hemos recogido en esta investigación nos aproximan a una disminución de la pena para los «delitos de preparación», porque desde su configuración no logran fundamentar de manera incuestionable la imposición de la sanción hasta ahora prevista.

Aceptar una pena inferior en los delitos de preparación, puede explicarse por diversos argumentos como los señalados en esta contribución. En esa línea, la justificación se da a razón de una valoración de carácter global tanto de la gravedad de la conducta como de la necesidad preventiva representada en la acción efectuada por el agente. No obstante, como dijimos, la disminución de la sanción es tan sola uno de los aspectos centrales en esta materia, por eso, pasemos a desarrollar los criterios para la inclusión de estas normas en el Código Penal.

\section{REFLEXIÓN PERSONAL}

1. Los «delitos de preparación», como demostramos, se caracterizan por ser tipos penales que violan varios principios básicos del Derecho Penal. Son figuras que reposan en la parte especial, aunque el castigo de la pena en algunos casos dependerá de la sanción prevista en otro precepto, es decir, son tipos que contiene remisión normativa; pero en otros, la disposición de la sanción goza, por así decirlo, de plena autonomía ${ }^{66}$. Continuando con las características, podríamos afirmar que son conductas de «gestación» con las

${ }^{66}$ Este es el caso, por ejemplo, del art. 183 ter, porque la pana está fijada de forma independiente en el contenido del mismo precepto. Mientras que el art. 400 aunque es un «delito de preparación», la pena está conectada a la prevista en el tipo de falsedades, es decir, el legislador remite la sanción a la de un tipo base, rompiendo en cierto grado parte de la autonomía, pero sigue estando en la parte especial, lo cual lo hace en cierto modo un tipo autónomo. Sin embargo, la pena prevista para el art. 400 es la misma que la señalada en el tipo de perfecta realización, estada consumada. 
cuales se pretende alcanzar la comisión de un ulterior delito, asimismo, puede decirse que son formas delictivas que no responden a lo que tradicionalmente entendemos por inter criminis, es decir, proceso o etapas para el desarrollo del delito, de ahí también deviene su incompatibilidad con los principios básicos del Derecho Penal. En efecto, mediante su ejecución no se percibe un daño del otro bien jurídico protegido en términos materiales. Aunque se produjere el resultado que se quiere evitar, los bienes jurídicos que se verían lesionados son recuperables en su inmensa mayoría y, además, ya están protegidos mediante otros preceptos que reposan en el mismo cuerpo legal, Código Penal.

En esto delitos también se aprecia que la entidad del daño es inferior tanto en el riesgo cuantitativo que se produce como en el resultado normativo. Pero ante todo, llama la atención que algunas cualidades que el legislador ha resaltado durante mucho tiempo no aparezcan aquí. Nos referimos a los supuestos que constituyen un mayor merecimiento de pena, esto es, el mayor daño ocasionado ${ }^{67}$.

Así como en los «actos preparatorios punibles» existen una serie de criterios para admitir el adelantamiento de la intervención, por coherencia legislativa deberán existir para los «delitos de preparación», pues ambos se ubican en la preparación delictiva, mejor dicho, ambos corresponden a la idea de excepcionalidad. Por todo esto, propongo que para incluir «delitos de preparación» el Código Penal deberán estar presentes dos criterios:

- El primero, ha de acudirse a esta técnica, únicamente, para salvar bienes jurídicos de primer nivel, es decir, todos aquellos que sean de carácter irrecuperable;

- El segundo, esta forma de preparación habrá de reservarse para supuestos que representen un una amenaza lo suficientemente relevante desde la preparación ${ }^{68}$.

${ }^{67}$ Sin ir más lejos. Así como la realización dolosa de un delito siempre se considera más grave que la realización imprudente, también estos principios elementales de culpabilidad y de proporcionalidad deberían inspirar la técnica de tipificación en los delitos de preparación (art. $13 \mathrm{CP}$ ).

${ }^{68}$ El legislador no se centra en la protección de un interés social, puesto que ya ese ejercicio se empleó pensando en evitar un resultado mediante la inclusión del tipo base. Mientras que ahora tipifica para evitar la mera preparación que, como decíamos en líneas anteriores, es un estado que se escapa de sus manos. Por ejemplo, la prohibición de estafar fue empleada en su oportunidad y es una consecuencia derivada de la protección del patrimonio económico. En tanto que la prohibición representada en los «delitos de preparación» puede verse como el resultado de una protección para los mismos bienes jurídicos, aunque se resalte una sobrevaloración. No obstante, a nuestro juicio, el valor está conce- 
En nuestra propuesta, siguiendo en buena parte a los autores arriba citados, entendemos las conductas de preparación como un género en el que podrían ubicarse perfectamente tanto los «delitos de preparación» como los «actos preparatorios punibles», dado que se trata de un ámbito excepcional.

Los «delitos de preparación» se caracterizan así, positivamente, como acciones referidas en un estado de "elaboración delictiva». Pero su diferenciación respecto a los «actos preparatorios punibles» va más allá como una figura negativa o rasgo negativo, esto es, como preceptos dependientes de un tipo señalado en la Parte Especial. La punibilidad de los «delitos de preparación» y de los «actos preparatorios punibles», como fenómeno de anticipación penal, no comparten el mismo fundamento, al repasar los requisitos para admitir las figuras previstas en los actos preparatorios punibles se atiende a una serie de razonamientos que no pueden compararse con los «delitos de preparación». De este modo, como ocurre en estos últimos, no basta con la intención o, de otro modo, con la mera posesión de instrumentos destinados a la comisión de una estafa para que exista conspiración o proposición para realizar un delito contra el patrimonio económico (art. 248.2 b]). Tampoco es suficiente con la mera capacitación o adiestramiento para constituir la proposición para cometer un delito de terrorismo (art. 509), sino que será preciso que haya una resolución firme y decidida de un sujeto para consumar el delito $y$, tras ello, invitar a otros a participar en él.

Así las cosas, nos volvemos a preguntar respecto a otra diferencia entre los «actos preparatorios punibles» y los denominados «delitos de preparación»... Pues bien, como dijimos, lo que los hace diferentes es la medida de incremento del riesgo que a sus características típicas responden. Afirmamos que la distinción entre «delitos de preparación» $\mathrm{y}$ «actos preparatorios punibles» se fundamenta en fuertes criterios de prevención y aunque parezca ilógico las consecuencias seguirán siendo así: a mayor riesgo, menor gravedad de pena y a menor riesgo de lesión, mayor extensión de la responsabilidad criminal.

Los «actos preparatorios punibles» son, por tanto, aquellas figuras que mediante la inclusión de sujetos hacen posible la reacción penal a razón del incremento del riesgo. Pues se acredita que el delito que se pretende realizar concurrirán los elementos necesarios para realizar la infracción, en gran parte la decidida y firme resolución de los sujetos involucrados, pues hablamos de una potencial lesividad que va camino a la consumación.

Es sabido por casi todos que para apreciar el incremento del riesgo en una conducta podemos fijarnos en el acto ejecutado; también la materialización de los actos potencialmente lesivos son pautas valorativas para determinar el

dido o se refiere a la posibilidad representada en el estado de preparación y en la posibilidad de alcance que este representa. 
riesgo típico relevante a efectos de imputación. Desde nuestro punto de vista, el ámbito de la preparación delictiva no puede resumirse simplemente con la adquisición de materiales o artefactos necesario para delinquir; ya que sancionar aspectos o conductas que se ubique en una zona muy alejada de la propia ejecución y a pasos previos de la tentativa nos introduciría a un Derecho penal excesivo, por no decir innecesario. Dijimos, aunque entre líneas, que el criterio representado en la proposición era insatisfactorio si no lo «veíamos» como una forma de participación intentada, inducción. La apreciación de la conducta debe emitirse comparando ex ante la posibilidad del delito representado en la aportación (en este caso un aporte inmaterial), podemos decir que si la probabilidad de cometer el injusto se incrementa sustancialmente para la obtención del resultado, basta decir que el incremento se evidencia en la consecución del deseo criminal que surge gracias a al inductor, salvo que, por circunstancias concretas la conducta no hubiera sido lo suficientemente firme como para despertar la idea.

Es de sobra conocido que estas contribuciones han de apreciarse en los «actos preparatorios punibles» como tipos dependientes y pueden «valorarse» tanto en la fase ejecutiva como en fase de preparación, aunque lo ideal es evitar el aporte de forma compartida, puesto que puede contribuir a la renuncia del sujeto o derivar en una tentativa de proposición (impune). El criterio más aconsejable, sin duda, es el referido a la contribución en fase ejecutiva, pero no podemos pasar por alto que estamos en formas intentadas de participación, por lo que se podrían presentar disminuciones en las posibilidades por distintos motivos como la idoneidad de la incitación por parte del autor.

Para cerrar, los «delitos de preparación» no se reconoce la inmediatez del peligro respecto a otras figuras de anticipación (delitos de peligro concreto, por ejemplo). Por todo eso, no solo se necesitan disminuir las penas actualmente previstas, no solo es necesario criterios restrictivos para su interpretación, sino, además, necesitamos contar con pautas específicas para poder acudir a esta controvertida figura de anticipación penal, y sostengo que son controvertidas porque distan de su cercanía con los principios básicos del Derecho Penal.

\section{VIII.CONCLUSIONES}

No es legítimo considerar a las actitudes delictivas como elemento objetivo típico, pues por si solas no representan nunca ninguna clase peligro para un bien jurídico, esto es lo que en parte ocurre con los «delitos de preparación». El objeto de valoración en los «delitos de preparación» está siempre en pretender despojar al criminal del dominio de un resultado posible o hipotético. 
El sentido de los «delitos de preparación» como instrumentos de anticipación penal no radica en la protección de un bien jurídico, sino en las conductas encaminadas o dirigidas a preparar la ejecución de otro delito.

Los «delitos de preparación» son una figura muy cercana a la intromisión de asuntos internos que en todo caso podría colisionar con las esferas más íntimas de la libertad; de ahí la necesidad de proponer criterios específicos para admitir si inclusión el Código Penal. Si no se establecemos límites a los «delitos de preparación» el panorama será el siguiente. Entre menos acciones se realicen, a pesar de que la posible lesión del bien jurídico esté más distante la condena será mayor (pena equiparada al resultado). Y entre más conductas se ejecuten, buscando la consumación del resultado, aunque no se consiga, la pena será menor (pena por tentativa). Entre más lejos estemos del resultado, tendremos menos sanción (pena de preparación). Por todo esto, del mismo modo se requiere la observación de los criterios que proponemos en esta contribución.

\section{BIBLIOGRAFÍA}

Alonso Rimo, Alberto, «Los nuevos delitos de ¿desórdenes? ¿públicos? Especial referencia a los tipos de incitación o de refuerzo de la disposición a delinquir (art. 557.2 y 559 CP)», Estudios Penales y Criminológicos, 35 (2015), 371.

BARBer Burusco, Soledad, Los actos preparatorios del delito: Conspiración, proposición y provocación, (Comenares: Granada, 2004), 148.

BeníteZ OrtúZar, Ignacio. F., «Delitos contra el orden público», en Lorenzo Morillas Cueva dir., Sistema de Derecho penal. Parte Especial, 2. ${ }^{a}$ ed., (Madrid: Dikinson, 2016), 1361-1363.

CAmpo Moreno, Juan Carlos, Los actos preparatorios punibles, (Valencia: Tirant lo Blanch, 2000), 23.

Corcoy Bidasolo, Mirentxu, Delitos de peligro y protección de bienes jurídicopenales supraindividuales (Valencia: Tirant lo Blanch, 1999), 282-286.

Domínguez Correa, Marcelo, El desistimiento de la tentativa, (Buenos Aires/Montevideo: BdF, 2013), 114-145.

Kublen, Lotbar, «Bienes Jurídicos y nuevos tipos de delito», en Límites al Derecho penal. Principios operativos en la fundamentación del castigo, edit. Por Andrew von Hirsch/Kurt Seelmann/Wolfgang Wohlers (Barcelona: Atelier, 2012), 225229.

Mir Puig, Santiago, Derecho penal. Parte general, 10. ${ }^{\mathrm{a}}$ ed., (Barcelona: Reppertor, 2015), 350-351.

Muñoz Conde, Francisco y García Arán, Mercedes, Derecho Penal. Parte espe-

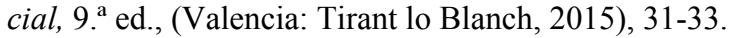

PuschKe, Jens, «Origen, esencia y límites de los tipos penales que elevan actos preparatorios a la categoría de delito», Indret Penal 4 (2010), 9.

Reyes Alvarado, Yesid, El delito de tentativa, (Montevideo/Buenos Aires: BdF, 2016), 106-111. 
Sola Recha, Esteban, La llamada tentativa inidónea del delito. Aspectos básicos, (Granada: Comares, 1996), 74-75; entre otros.

Von Hirsch, Andrew y WoHLERs, Wolfgang, «Teoría del bien jurídico y estructura del delito. Sobre los criterios de una imputación justa», en La teoría del bien jurídico. ¿Fundamento de legitimación del Derecho penal o juego de abalorios dogmáticos?, en trd. Beatriz Spínola Tártalo, y Roland Hefendehl/Andrew Von Hirsch/Wolfgang Wohlers edtrs., (Madrid: Marcial Pons, 2007), 287.

\section{JURISPRUDENCIA:}

SAP Burgos 69/2014, 21 de febrero de 2014.

TS 174/2015, 14 de mayo de 2015.

STC 177/2015, 22 de julio de 2015.

STS 323/2006, 22 de marzo de 2006.

STS 480/2009, 22 de mayo de 2009.

STS 849/2013, 12 de noviembre de 2013.

STS 956/2013, 17 de diciembre de 2013.

STS 689/2014, 21 de octubre de 2014.

STS 771/2014, 19 de noviembre de 2014.

STS 277/2015, 3 de junio de 2015.

STS 673/2015, 4 de noviembre de 2015.

STS 428/2016, 19 de mayo de 2016.

STS 9/2017, 18 de enero de 2017.

STS 109/2017, 22 de febrero de 2017.

STS 149/2017, 9 de marzo de 2017.

STS 747/2017, 21 de noviembre de 2017.

STS 177/2018, 12 de abril de 2018.

STS 214/2018, 8 de mayo de 2018.

STS 660/2018, 17 de diciembre de 2018.

STS 241/2019, 9 de mayo de 2019. 


\title{
LÍMITES PARA LOS DELITOS DE PREPARACIÓN: CRITERIOS RESTRICTIVOS PARA SU INCLUSIÓN EN EL CÓDIGO PENAL
}

\author{
Limits for preparation crimes: restrictive criteria for \\ inclusion in the criminal code
}

\author{
Roberto Cruz Palmera \\ Profesor Doctor (LL.M.) \\ Universidad Autónoma del Caribe
}

http://dx.doi.org/10.18543/ed-68(1)-2020pp257-285

\section{Copyright}

Estudios de Deusto es una revista de acceso abierto, lo que significa que es de libre acceso en su integridad. Se permite su lectura, la búsqueda, descarga, distribución y reutilización legal en cualquier tipo de soporte sólo para fines no comerciales, sin la previa autorización del editor o el autor, siempre que la obra original sea debidamente citada y cualquier cambio en el original esté claramente indicado

Estudios de Deusto is an Open Access journal which means that it is free for full access, reading, search, download, distribution, and lawful reuse in any medium only for non-commercial purposes, without prior permission from the Publisher or the author; provided the original work is properly cited and any changes to the original are clearly indicated. 